\title{
Chiral Recognition of Zinc(II) Ion Complexes Composed of Bicyclo[3.3.0] Octane-2,6-Diol and $s$-Naproxen Probed by Collisional-Induced Dissociation
}

\author{
Chong-Tian Yu, Yin-Long Guo, Guo-Qiang Chen, and Yu-Wu Zhong \\ Shanghai Institute of Organic Chemistry, Chinese Academy of Sciences, Shanghai, People's Republic of China
}

Chiral recognition of racemic bicyclo[3.3.0] octane-2,6-diol(B) was achieved in the gas phase using $s$-Naproxen(A) as reference, using the kinetics of competitive unimolecule dissociation of tetrameric zinc(II)-bound complexes by electrospray ionization Fourier transform ion cyclotron resonance mass spectrometer(ESI-FTMS). As undergoing a mild competitive collision-induced dissociation(CID) experiment with a constant pressure argon gas introduced by leak valve, the tetrameric cluster ion $\left[\mathrm{A}_{2} \mathrm{~B}_{2} \mathrm{Z}_{\mathrm{n}}(\mathrm{II})-\mathrm{H}\right]^{+}$forms only two trimeric ions and $R_{\text {chiral }}$ is subsequently obtained in the kinetic method. Further studies obtained the difference of Gibbs free energy of $\left[\mathrm{ABZ}_{\mathrm{n}}(\mathrm{II})-\mathrm{H}\right]^{+}\left(\Delta \Delta \mathrm{G}_{\mathrm{ABZn}(\mathrm{II})-\mathrm{H}]^{+}}\right)$by dissociating $\left[\mathrm{A}_{2} \mathrm{BZ}_{\mathrm{n}}(\mathrm{II})-\mathrm{H}\right]^{+}$, resulting two fragment ions $\left[\mathrm{ABZ}_{\mathrm{n}}(\mathrm{II})-\mathrm{H}\right]^{+}$and $\left[\mathrm{A}_{2} \mathrm{Z}_{\mathrm{n}}(\mathrm{II})-\mathrm{H}\right]^{+}$, which can be established to a linear relationship between $\Delta \Delta G_{[\mathrm{ABZn}(\mathrm{II})-\mathrm{H}]^{+}}$and $R_{\text {chiral }}^{\prime}$ basing on the kinetic method. The value of

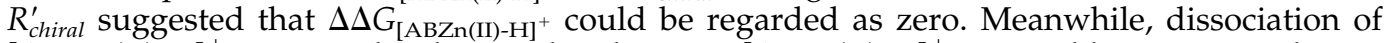
$\left[\mathrm{AB}_{2} \mathrm{Z}_{\mathrm{n}}(\mathrm{II})-\mathrm{H}\right]^{+}$generated only one daughter ion $\left[\mathrm{ABZ}_{\mathrm{n}}(\mathrm{II})-\mathrm{H}\right]^{+}$in a stable pressure. Thus, a linear relationship was established between the difference of Gibbs free energy of $\left[\mathrm{AB}_{2} \mathrm{Z}_{\mathrm{n}}(\mathrm{II})\right.$ $\mathrm{H}]^{+}\left(\Delta \Delta G_{\left[\mathrm{AB}_{2} \mathrm{Zn}(\mathrm{II})-\mathrm{H}\right]^{+}}\right)$and $R_{\text {chiral }}^{\prime \prime}$ if the $\Delta \Delta G_{[\mathrm{ABZn}(\mathrm{II})-\mathrm{H}]^{+}}$can be negligible. Because there is also a linear relationship of $R_{\text {chiral }}$ in the tetrameric ion $\left[\mathrm{A}_{2} \mathrm{~B}_{2} \mathrm{Z}_{\mathrm{n}}(\mathrm{II})-\mathrm{H}\right]^{+}$and the Gibbs energy difference of trimeric cluster ion $\left[\mathrm{A}_{2} \mathrm{BZ}_{\mathrm{n}}^{+}(\mathrm{II})-\mathrm{H}\right]\left(\Delta \Delta \mathrm{G}_{\left[\mathrm{A}_{2} \mathrm{BZn}(\mathrm{II})-\mathrm{H}\right]^{+}}\right)$plus that of $\left[\mathrm{AB}_{2} \mathrm{Z}_{\mathrm{n}}(\mathrm{II})-\mathrm{H}\right]^{+}$, $\Delta \Delta G_{\left.\left[A_{2} B_{n}(\mathrm{III})-\mathrm{H}\right]+\right]}$ is easy to be calculated in the dissociation process of tetrameric ion. Stable of $R_{\text {chiral }} R_{\text {chiral }}^{\prime}$ and $R_{\text {chiral }}^{\prime \prime}$ under different pressures show $\mathrm{T}_{\text {eff }}$ does not affect the chiral recognition of cluster ions in the condition selected. If an only-one-daughter-ion fragment process of $\left[\mathrm{A}_{2} \mathrm{BZ}_{\mathrm{n}}(\mathrm{II})-\mathrm{H}\right]^{+}$was existed, $R_{\text {chiral }}^{\prime \prime \prime}$ relating to this dissociation would be calculated just like $R_{\text {chiral }}^{\prime \prime}$ of $\left[\mathrm{AB}_{2} \mathrm{Z}_{\mathrm{n}}(\mathrm{II})-\mathrm{H}\right]^{+}$does. Conclusion was obtained that $\left[\mathrm{A}_{2} \mathrm{BZ}_{\mathrm{n}}(\mathrm{II})-\mathrm{H}\right]^{+}$makes more contribution to chiral recognition of tetrameric ion measured by kinetic method than $\left[\mathrm{AB}_{2} \mathrm{Z}_{\mathrm{n}}(\mathrm{II})-\mathrm{H}\right]^{+}$does as $R_{\text {chiral }}^{\prime \prime \prime}$ and $R_{\text {chiral }}^{\prime \prime}$ were applied as index to evaluate the Gibbs free energy difference of these two trimeric cluster ions. Further discussion shows that steric interactions and $\pi-\pi$ stacking interactions are the major factors responsible for the observed efficient chiral recognition in this system. (J Am Soc Mass Spectrom 2004, 15, 795-802) (C) 2004 American Society for Mass Spectrometry

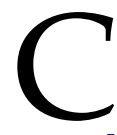
hiral recognition is of an important area in chemical synthesis and biological research since it often determines the asymmetry reaction activity [1] or bioactivity of a substance [2]. Up to date, many methods have been developed for the chiral recognition of organic compounds, including circular dichroism [3], chromatography [4], capillary electrophoresis [5], nuclear magnetic resonance [6], and mass spectrometry. Especially, the approach based on Mass spectrometry draws much attention on the studies of chiral recognition because of its sensitivity, speed, and simplicity. Moreover, this method eliminates the inter-

Published online April 2, 2004

Address reprint requests to Dr. Y.-L. Guo, Shanghai Institute of Organic Chemistry, Chinese Academy of Sciences, Shanghai 200032, People's Republic of China. E-mail: ylguo@mail.sioc.ac.cn ference from solvent or a stationary phase, therefore allowing an intrinsic evaluation of the interactions in the diastereomeric complex and providing structural confirmation in the gas phase. The introduction of soft ionization approaches to mass spectrometry, including fast atom bombardment, matrix-assisted laser desorption ionization and electrospray ionization, allows formation of the gas phase ions of non-covalent or weaklybound complexes. These ionization methods are also helpful to the chiral recognition studies of some important nonvolatile chiral compounds such as amino acids and sugars.

As is well known, MS is insensitive to chirality difference [7]. Thus, key procedures have to be applied for chiral recognition by MS: (1) To co-inject a chiral compound in the compound-matrix system as a reference, and (2) to detect certain differences in the result- 
ing diastereomeric intermolecular interaction. The earliest chiral distinction by MS was reported by Fales and Wright in 1977 [8]. They showed that chirality of dialkyl tartrates affected the relative abundance of the respective proton-bound dimers. Since then, Many elegant methods have been developed, such as: (1) Discriminating the intensities of the pair of diastereomeric complexes in one stage mass spectra based on their different stabilities [9-22]. Usually, an isotope-labeled form of one of the enantiomers is used which can conveniently determine the difference of chiral recognition at one time [16-22]. (2) Discriminating the abundance ratios of daughter ion to parent ion after the mass-selected diastereomeric complexes are fragmented in second stage mass spectra [23-25]. In this method, the most important point is that the condition in the experiments of two enantiomers should be identical. Performing repeated experiments has the capability of improving the reproducibility. The advantage of this method is that it is simple and easy to perform. (3) Discriminating the intensities of product or reactant complexes in second stage mass spectra, based on the different ion/ molecule reaction rates of formation of a pair of diastereomeric host-guest complexes or that of exchange of the complexes with a new guest [26-36]. (4) Comparing the dissociation kinetics of diastereomeric complexes based on two competitive dissociation pathways in a collisional induced dissociation experiment, which is popularly known as the kinetic method [37-47]. All these methods mentioned above need a chiral host molecule or an optically pure reagent to associate with the target compound forming an enantioselective intermolecular interaction system. There are several variations with regard to the selection of the reference. Tartaric acid ester [48], mandelic acid, or amino acid [49] is applied to form a dimerization or association system for chiral recognition. It is also possible to discriminate the enantiomer in a host-guest system applying chiral crown ether [26-30], cyclodextrin [31$36]$, and some kinds of antibiotic drug with macrocyclic structure [50]. Recently, the metal binding complexes of natural chiral amino acids have commonly been utilized as chiral selectors [37-41, 43-47]. It has been shown that these chiral amino acids with an aromatic side chain provide the greatest chiral distinction $[24,25$, $37,38]$. Furthermore, the electron-donating nitrogen in Trp and His appears to be important for substantial chiral discrimination [24]. The metal ions of lithium, cobalt, antimony, and copper have been used to assist the chiral reference in achieving chiral recognition [12, 37-41]. Copper ion is the most utilized metal ion and the characteristics of copper associated complexes have also been studied 51-55]. Zinc ion has also been used as a binding metal ion to effect good chiral recognition of sugars [45]. In our recent job, we also show a high degree of chiral recognition capabilities with double charge zinc (II) and copper (II) tetrameric complexes [56].

Herein, a anti-inflammation drug, S-Naproxen (S-A) is selected as a chiral reference and zinc(II) as an<smiles>COc1ccc2cc([C@@H](C)C(=O)O)ccc2c1</smiles>

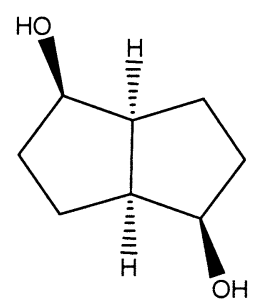

(-)-Octane

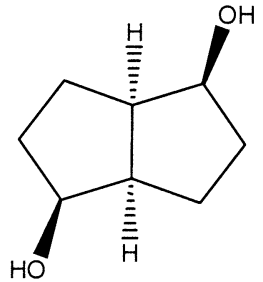

(+)-Octane
Scheme 1. Molecular structure of Naproxen and Octane.

auxiliary metal ion to study its chiral recognition capability of 2,6-dihydroxy-bicyclo[3.3.0] octane (B). Compound B is a good initial reactant for synthesizing an optical pure product and its derivatives also can be selected as chiral ligands for the catalytic enantioselective addition of diethylzinc to aldehydes [57]. There are four chiral centers and a $\mathrm{C}_{2}$-symmetric axial in Compound $\mathrm{B}$. We have succeeded in resolution of the racemic compound to obtain $(-) \mathrm{B}$ and $(+) \mathrm{B}$. In the multimeric complex formed by A and B, we assumed that only one hydroxyl group in Compound A can chelate with Zinc(II) because of long steric distance between two hydroxyl groups. As for the structure of naproxen, it has one chiral central atom and chelates with Zinc(II) by carboxylate group (both molecule structures are shown in Scheme 1. In this report, a good chiral discrimination is obtained with the forming of multimeric complexes followed by CID experiment in ion cell. CID experiment was performed by selecting the tetrameric complexes, i.e., $\left[\mathrm{A}_{2} \mathrm{~B}_{2} \mathrm{Zn}-\mathrm{H}\right]+$ colliding with argon gas maintaining a stable pressure for obtaining a tandem mass spectra. A good chiral discrimination between (-)-B and (+)-B can be achieved by applying a suitable comparison of two dissociation pathways. Furthermore, the possible intrinsic chiral recognition mechanism of $\left[\mathrm{A}_{2} \mathrm{~B}_{2} \mathrm{Zn}-\mathrm{H}\right]+$ in gas phase is discussed by further studying the chiral recognition of trimeric ion, i.e., $\left[\mathrm{A}_{2} \mathrm{BZn}(\mathrm{II})-\mathrm{H}\right]^{+}$and $\left[\mathrm{AB}_{2} \mathrm{Zn}(\mathrm{II})-\mathrm{H}\right]^{+}$.

\section{Experimental}

\section{Preparation of the Samples}

The enantiomerically pure $(1 S, 2 R, 5 S, 6 R)$ - and $(1 R, 2 S, 5 R, 6 S)$-B ((-)-B and (+)-B) were obtained [57], and were identified by IR spectra, ${ }^{1} \mathrm{H}$ NMR, ${ }^{13} \mathrm{C}$ NMR, and high resolution MS. Anhydrous $\mathrm{ZnSO}_{4}$ were purchased from Shanghai technology research institute of 
Shanghai as analytically pure reagents; they were used without further purification. S-Naproxen was kindly provided by Shanghai Agency of Charioteer Pharmaceutical Factory (Xianju, Zhejiang Province, China). The enantiomeric purity of all optical subtance was determinated by HPLC. ee of S-naproxen and B all exceed 99\%. Anhydrase $\mathrm{Zn}(\mathrm{II})$ complexes were generated by electrospraying 20/80 water/methonal solutions containing a mixture of the $S$-Naproxen and one of enantiomerically pure reference Compound $B$, at a concentration of $4 \times 10^{-6} \mathrm{M}$ each, and $1 \times 10^{-6} \mathrm{M}$ zinc sulfide.

\section{Instrumentation and Methods}

All MS and tandem MS experiments were performed on a Bruker Daltonics APEX III ESI-FTMS equipped with a 7.0 tesla shielded superconducting magnet. The vacuum was maintained by means of mechanical vacuum pumps followed by turbomolecular pumps in two different regions: ion source (maintained $\sim 5.0 \times 10^{-7}$ mbar) and cell region (maintained $\sim 2.7 \times 10^{-10} \mathrm{mbar}$ ). The ions were generated from an external electrospray ionization source. Typically, the electrospray flow rate is $2 \mu \mathrm{L} / \mathrm{min}$, maintained by a syringe pump. The spray is directed into a heated glass capillay drying tube with $\mathrm{Ni}$-coated in both ends remained at temperature about $450 \mathrm{~K}$. Typically, high voltage about $4000 \mathrm{~V}$ is applied between the endplate and the spray needle. Then the ions are accumulated in the RF-only hexapole ion storage region for $0.5 \mathrm{~s}$, focused and steered through the ion transfer region. They were finally transferred into the "infinity" cell with a "sidekick" voltage perpendicular to magnetic field for trapping and detection. All of parameters from the ion generation to trapping was optimized on the tuning pars based on the maximum intensity of parent ion acchieve. In tandem MS experiments, the parent ion of interests are isolated with the isolation sweep attenuation/isolation pulse length of $21 \mathrm{~dB} / 0.8 \mathrm{~ms}$ and then collided with argon gas. The collision gas argon was introduced into the cell through a variable leak valve to maintain a stable pressure; the pressure of argon must be kept identical for measurements of the $(+)$ and $(-)$ enatiomers. The dissociation process strongly depends on the pressure in the cell and the collision time. The more argon gas introduced into the cell, the more fragment ion will be induced quickly in a short collision time. Thus, one delay of about 1 s was applied after the parent ion was isolated. During this delay period, no activation pulse was needed and the fragment process was spontaneously generated, which was dependant on the initial kinetic energy of ions. After the delay period mass spectra was acquired by the positive ion mode with broadband detection (eight scans per experiment each) from 100 to 1500 Da using $128 \mathrm{~K}$ data points. So the mass spectra do reflect the dissociation process of those isolated ion in $1 \mathrm{~s}$ time window of delay. Furthermore, pressure from $1.0 \times$ $10^{-9}$ mbar to $2.5 \times 10^{-8}$ mbar was adjusted to investigate the effect of argon gas pressure in the cell on the enantiodiscrimination. Generally, to minimize the chiral recognition error produced by the instrument, each experiment was performed subsequently in the pair of enantiomers. All experimental sequences, including scan accumulation and data processing, were performed with XMASS 6.0.0 software on a DELL computer with 256-MB RAM, 40-GB harddrive. The instrument was calibrated externally with a 50:50 water/methanol solution of Angiotensin I.

\section{Results and Discussion}

\section{Chiral Recognition of Tetrameric Ion by Kinetic Method}

In the tandem mass spectrometric experiments, the diastereomeric cluster ions were dissociated to several fragment ions. Cooks and his coworker [37-40, 43-47] had developed a way called "kinetic method" to quantify the chiral effects and this approach had been successful in the studies on the chiral effect of amino acids and $\alpha$-hydroxy acids. Generally, this method involved a comparison of only the two-fragmentation branch path by collision-induced dissociation(CID) of trimeric transition metal ion-bound cluster ions.

Initially, we performed the SORI-CAD experiment of the cluster ion, i.e., $\left[\mathrm{A}_{2} \mathrm{~B}_{2} \mathrm{Zn}(\mathrm{II})-\mathrm{H}\right]^{+}$which was subjected to a supplementary ion activation pulse to resonantly excite it and then allow it to dissociate with argon gas introduced by pulse valve. However, such dissociation process gave rise to several product ions and fragment ions such as $\left[\mathrm{A}_{2} \mathrm{BZn}(\mathrm{II})-\mathrm{H}\right]^{+},{ } \mathrm{AB}_{2} \mathrm{Zn}(\mathrm{II})-$ $\left.\mathrm{H}^{+},{ }, \mathrm{B}_{2} \mathrm{Zn}(\mathrm{II})-\mathrm{H}\right]^{+}$, and $[\mathrm{ABZn}(\mathrm{II})-\mathrm{H}]^{+}$etc., but not just the two-branch fragment way. No matter how carefully we tune the parameters of activation pulse in SORICAD experiment, it is hard to achieve only the twoproduct ion of $\left[\mathrm{A}_{2} \mathrm{~B}_{2} \mathrm{Zn}(\mathrm{II})-\mathrm{H}\right]^{+}$. Thus, we should find another "gentle" way to perform the CID experiment.

Fortunately, if the collision gas argon were introduced into the cell by a variable leak valve to keep a constant base pressure in it, the dissociation process of tetrameric ion would spontaneously generate only twoproduct ions, i.e., $\left[\mathrm{A}_{2} \mathrm{BZ}_{\mathrm{n}}(\mathrm{II})-\mathrm{H}\right]^{+}(m / z$ 635) and $\left[\mathrm{AB}_{2} \mathrm{Z}_{\mathrm{n}}(\mathrm{II})-\mathrm{H}\right]^{+}(m / z$ 577). The reason, we assume, is attributable to the internal energy required for the dissociation process just coming from the translation of initial kinetic energy, which is less than the kinetic energy deduced by activation pulse. It should be noted that if more argon gas were introduced into the cell, another fragment ion, i.e., $\left[\mathrm{ABZ}_{n}(\mathrm{II})-\mathrm{H}\right]^{+}$, would be induced. Finally, we found out the pressure value about $2.0 \times 10^{-9} \mathrm{mbar}$ is suitable for the tetrameric ion $\left[\mathrm{A}_{2} \mathrm{~B}_{2} \mathrm{Zn}(\mathrm{II})-\mathrm{H}\right]^{+}$to only generate two fragment ions, as shown in Figure 1. The intensity of fragment ion $\left[\mathrm{ABZ}_{\mathrm{n}}(\mathrm{II})-\mathrm{H}\right]^{+}$in this pressure condition was less than $1 \%$ of base peak in second stage mass spectra and its effect on the result could safely be ignored. In fact, we found that the $R_{\text {chiral }}$ (defined in eq 2) calculated in different pressures from $1.0 \times 10^{-9}$ mbar to $2.5 \times 10^{-8}$ 

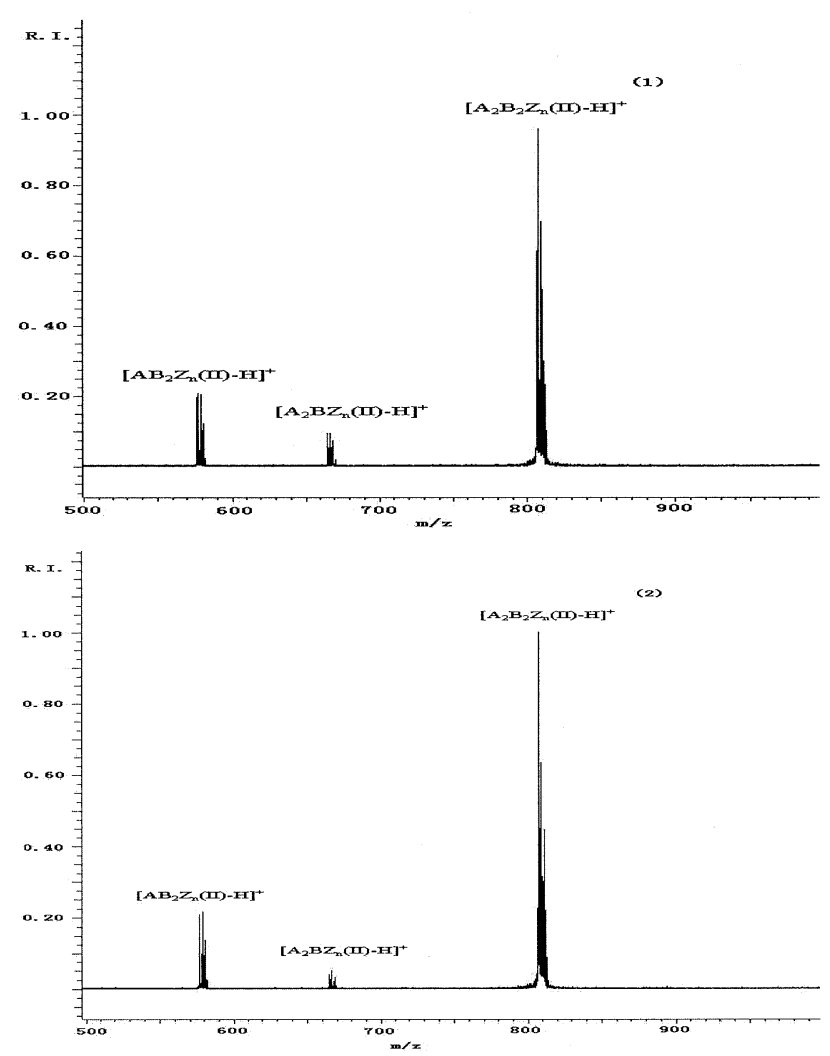

Figure 1. ESI FTMS tandem mass spectra of $\left[\mathrm{A}_{2} \mathrm{~B}_{2} \mathrm{Zn}(\mathrm{II})-\mathrm{H}\right]^{+}$ from solutions of 20:80(vol:vol) water:methonal containing zinc(II) salts, S-naproxen and (+)-Octane(upper spectrum) or (-)-Octane(lower spectrum).

mbar varied very little, which we assumed was reasonable in the range of system error. Now the chiral recognition of $\left[\mathrm{A}_{2} \mathrm{~B}_{2} \mathrm{Zn}(\mathrm{II})-\mathrm{H}\right]^{+}$can be studied by the kinetic method. The branch ratio $\mathrm{R}$ was calculated, by eq 1 ,

$$
R=I_{\left[A B_{2} Z n(I I)-H\right]^{+}} / I_{\left[A_{2} B Z n(I I)-H\right]^{+}}
$$

where $I_{\left[\mathrm{AB}_{2} \mathrm{Zn}(\mathrm{II})-\mathrm{H}\right]^{+}}$and $I_{\left[\mathrm{A}_{2} \mathrm{BZn}(\mathrm{II})-\mathrm{H}\right]^{+}}$is defined as the relative intensity of $\left[\mathrm{AB}_{2} \mathrm{Zn}(\mathrm{II})-\mathrm{H}\right]^{+}$and $\left[\mathrm{A}_{2} \mathrm{BZn}(\mathrm{II})-\mathrm{H}\right]^{+}$ respectively. When the analyte is (+)-B or (-)-B, $R$ is given as $R_{+}$or $R_{-}$and the chiral selectivity $R_{-}$to $R_{+}$, defined as $R_{\text {chiral }}$ measures the degree of chiral discrimination (eq 2):

$$
\begin{aligned}
R_{\text {chiral }} & =R_{-} / R_{+} \\
& =\frac{I_{\left[(S)-A((-)-B)_{2} Z n(I I)-H\right]^{+}} / I_{\left[((S)-A)_{2}(-)-B Z n(I I)-H\right]^{+}}}{I_{\left[(S)-A((+)-B)_{2} Z n(I I)-H\right]^{+}} / I_{\left[((S)-A)_{2}(+)-B Z n(I I)-H^{+}\right.}}
\end{aligned}
$$

Based on the above expression, the branch ratio $R_{+}$is $2.02(n=10, \operatorname{RSD}=3.0 \%)$, whereas $R_{-}$is $4.85(n=10$, RSD $=4.6 \%)$. The chiral selectivity, $R_{\text {chiral }}$ is therefore 2.40 in this case, which shows a good chiral selectivity.
From the kinetic method, the natural logarithm of the ratio of rate constant, $R$, is proportional to the Gibbs energy differences of two trimeric product ions in two competitive ways of fragmentation of mother tetrameric ion $\left[\mathrm{A}_{2} \mathrm{~B}_{2} \mathrm{Zn}(\mathrm{II})-\mathrm{H}\right]^{+}$, that is (eq 3),

$$
\mathrm{I} n / R=\frac{\Delta G_{\left[A B_{2} Z n(I I)-H\right]^{+}}-\Delta G_{\left[A^{2} B Z n(I I)-H\right]^{+}}}{R T_{e f f}}
$$

here, $\mathrm{R}$ is the gas law constant and $T_{\text {eff }}$ is the effective temperature of activated complex ion. Thus, the energy quantity, i.e., $\Delta \Delta \mathrm{G}_{\mathrm{tri}}$, which reflects the stereochemical interaction difference in the trimeic cluster, is expressed by eq 6 .

$$
\begin{aligned}
\Delta \Delta G_{t r i}= & {\left[\Delta G_{\left[(s)-A\left((-)-B_{2} Z n(I I)-H\right)^{+}\right.}\right.} \\
& \left.-\Delta G_{\left[((s)-A)_{2}(-)-B Z n(I I)-H\right]^{+}}\right] \\
& -\left[\Delta G_{\left[(s)-A((+)-B)_{2} Z n(I I)-H\right]^{+}}\right. \\
& \left.-\Delta G_{\left[((s)-A)_{2}(+)-B Z n(I I)-H\right]^{+}}\right] \\
= & R T_{\text {eff }} \ln \left(R_{\text {chiral }}\right)
\end{aligned}
$$

$\Delta \Delta \mathrm{G}_{\mathrm{tri}}$ can also be expressed by transforming the eq 4 to another form, that is,

$$
\begin{aligned}
\Delta \Delta G_{t r i}= & {\left[\Delta G_{\left[((s)-A)_{2}(+)-B Z n(I I)-H\right]^{+}}\right.} \\
& \left.-\Delta G_{\left[\left((s)-A^{2}(-)-B Z n(I I)-H\right]^{+}\right.}\right] \\
& +\left[\Delta G_{\left[\left((s)-A((-)-B)_{2} Z n(I I)-H\right]^{+}\right.}\right] \\
& -\Delta G_{\left[(s)-A((+)-B)_{2} Z n(I I)-H\right]^{+}} \\
= & R T_{\text {eff }} \ln \left(R_{\text {chiral }}\right)
\end{aligned}
$$

eq 5 suggest that the chiral selectivity observed in the tetrameric ion $\left[\mathrm{A}_{2} \mathrm{~B}_{2} \mathrm{Z}_{n}(\mathrm{II})-\mathrm{H}\right]^{+}$originated from the Gibbs energy difference of trimeric cluster ion $\left[\mathrm{A}_{2} \mathrm{BZ}_{\mathrm{n}}(\mathrm{II})-\mathrm{H}\right]^{+}$plus that of $\left[\mathrm{AB}_{2} \mathrm{Z}_{\mathrm{n}}(\mathrm{II})-\mathrm{H}\right]^{+}$. However, we could not point out which one contributed more to the chiral recognition. Therefore, for probing the enantiodiscrimination mechanism of tetrameric cluster ion, further experiment of two trimeric ion mentioned above have to be carried out.

\section{Chiral Recognition of Trimeric Ion by MS/MS Experiment}

Both $\left[\mathrm{A}_{2} \mathrm{BZ}_{\mathrm{n}}(\mathrm{II})-\mathrm{H}\right]^{+}$and $\left[\mathrm{AB}_{2} \mathrm{Z}_{\mathrm{n}}(\mathrm{II})-\mathrm{H}\right]^{+}$were isolated by removing all other ions under an isolation sweep. The argon gas pressure in cell was carefully adjusted from $1.0 \times 10^{-9}$ mbar to $2.5 \times 10^{-8} \mathrm{mbar}$, and then the selected ion was allowed to perform a mild collision with neutral for $1 \mathrm{~s}$.

When $\left[\mathrm{A}_{2} \mathrm{BZ}_{\mathrm{n}}(\mathrm{II})-\mathrm{H}\right]^{+}$was selected as parent ion, two daughter ions were generated, i.e., $\left[\mathrm{ABZ}_{\mathbf{n}}(\mathrm{II})-\mathrm{H}\right]^{+}(\mathrm{m} / \mathrm{z}$ $435)$ and $\left[\mathrm{A}_{2} \mathrm{Z}_{\mathrm{n}}(\mathrm{II})-\mathrm{H}\right]^{+}(\mathrm{m} / z$ 523). Based on the above the 
kinetic method, the relative abundance ratio $R^{\prime}$ is given by $R^{\prime}=I_{[\mathrm{ABZn}(\mathrm{II})-\mathrm{H}]^{+}} / I_{\left[\mathrm{A}_{2} \mathrm{Zn}(\mathrm{II})-\mathrm{H}\right]^{+}}$. The chiral selectivity is given by $R_{\text {chiral }}^{\prime}=R_{-}^{\prime} / R_{+}^{\prime}$, in which $R_{-}^{\prime}$ and $R_{+}^{\prime}$ represent the $R$ of complex with (-)-B and $(+)$-B, respectively. Calculation by the given equation showed that $R_{-}$and $R_{+}$was $7.23(n=5, \mathrm{RSD}=4.7 \%)$ and $7.73(n=5, \mathrm{RSD}$ $=9.5 \%)$, respectively. The value of $R_{\text {chiral }}^{\prime}$ is 1.07 , which showed little degree of chiral discrimination. Measurement under the conditions with different argon gas pressure in the cell also showed that the $R_{\text {chiral }}^{\prime}$ value is more or less close to unit. These results mean two points for the trimeric cluster ion $\left[\mathrm{A}_{2} \mathrm{BZ}_{\mathrm{n}}(\mathrm{II})-\mathrm{H}\right]^{+}$. First, variation of pressure did not result in the variation of $R_{\text {chiral }}^{\prime}$ in the range of pressure we adjusted. Second, a conclusion can be drawn that the difference of Gibbs free energy between $[\mathrm{A}(-)-\mathrm{BZn}(\mathrm{II})-\mathrm{H}]^{+}$and $\left[\mathrm{A}(+)^{-} \mathrm{BZn}(\mathrm{II})-\right.$ $\mathrm{H}]^{+}$is close to zero under the condition we applied; it was derived based on the following equation which reflect the relationship of Gibbs free energy and $R_{\text {chiral }}^{\prime}$. The difference of Gibbs free energy in diastereomeric complex ion $\left[\mathrm{ABZ}_{\mathrm{n}}(\mathrm{II})-\mathrm{H}\right]^{+}$is expressed by eq 11 :

$$
\begin{aligned}
\Delta \Delta G_{[A B Z n(I I)-H]^{+}}= & \Delta G_{[(s-A)(-)-B Z n(I I)-H]^{+}} \\
& -\Delta G_{[(s-A)(+)-B Z n(I I)-H]^{+}}
\end{aligned}
$$

Considering about the two branch fragment ways in the dissociation of $\left[\mathrm{A}_{2} \mathrm{BZ}_{\mathrm{n}}(\mathrm{II})-\mathrm{H}\right]^{+}$, the value of $\Delta \Delta G_{[\mathrm{ABZn}(\mathrm{II})-\mathrm{H}]}^{+}$can be obtained by the eq 7 :

$$
\begin{aligned}
R T_{\text {eff }} \ln R_{\text {chiral }} & =R T_{e f f} \ln R_{-} / R_{+} \\
& =\Delta G_{[A B Z n(I I)-H]^{+}}=\Delta G_{[A B Z n(I I)-H]^{+}}
\end{aligned}
$$

Because there must be no free energy difference between the same cluster ion $\left[\mathrm{A}_{2} \mathrm{Z}_{\mathrm{n}}(\mathrm{II})-\mathrm{H}\right]^{+}$, we could directly calculate the value of $\Delta \Delta G_{[\mathrm{ABZn}(\mathrm{II})-\mathrm{H}]^{+}}$from eq 7 and the result showed there was no obvious difference of the Gibbs free energy between $\left[\mathrm{A}(-)-\mathrm{BZ}_{\mathrm{n}}(\mathrm{II})-\mathrm{H}\right]^{+}$ and $\left[\mathrm{A}(+)-\mathrm{BZ}_{\mathrm{n}}(\mathrm{II})-\mathrm{H}\right]^{+}$.

As for another trimeric cluster ion $\left[\mathrm{AB}_{2} \mathrm{Z}_{\mathrm{n}}(\mathrm{II})-\mathrm{H}\right]^{+}$, we also performed the dissociation experiment of it under the same conditions as $\left[\mathrm{A}_{2} \mathrm{BZ}_{\mathrm{n}}(\mathrm{II})-\mathrm{H}\right]^{+}$, in which pressure ranged from $1.0 \times 10^{-9}$ mbar to $2.5 \times 10^{-8}$ mbar. In the dissociation process of $\left[\mathrm{AB}_{2} \mathrm{Z}_{\mathrm{n}}(\mathrm{II})-\mathrm{H}\right]^{+}$, only one daughter ion $\left[\mathrm{ABZ}_{\mathrm{n}}(\mathrm{II})-\mathrm{H}\right]^{+}$was observed. So we used the $\mathrm{R}_{-}^{\prime \prime}$ and $R_{+}^{\prime \prime}$ to represent the intensity ratio of the fragment ion $\left[\mathrm{ABZ}_{\mathrm{n}}(\mathrm{II})-\mathrm{H}\right]^{+}$to the parent ion $\left[\mathrm{AB}_{2} \mathrm{Z}_{\mathrm{n}}(\mathrm{II})-\mathrm{H}\right]^{+}$with $(-)-\mathrm{B}$ and (+)-B in it, respectively. $R_{\text {chiral }}^{\prime \prime}$ is 0.81 calculated by $R_{\text {chiral }}^{\prime \prime}=R_{-}^{\prime \prime} / R_{+}^{\prime \prime}$, in which $R_{+}^{\prime \prime}$ and $R_{-}^{\prime \prime}$ were 1.35 $(n=5, \mathrm{RSD}=5.7 \%)$ and $1.65(n=5, \mathrm{RSD}=3.3 \%)$. Furthermore, even if we varied the pressure of the cell, the value of $R_{\text {chiral }}^{\prime \prime}$ remained very stable though $R_{+}^{\prime \prime}$ and $R_{-}^{\prime \prime}$ both increased with cell pressure. $R_{+}^{\prime \prime}$ and $R^{\prime \prime}$ increase in the same trend and extent, which result in stability of $R_{\text {chiral }}^{\prime \prime}$.

Because only one daughter ion $\left[\mathrm{ABZ}_{\mathrm{n}}(\mathrm{II})-\mathrm{H}\right]^{+}$was generated in the dissociation process of parent ion $\left[\mathrm{AB}_{2} \mathrm{Z}_{\mathrm{n}}(\mathrm{II})-\mathrm{H}\right]^{+}$in the range of pressure we adjusted, a relationship was easyly established between $R^{\prime \prime}$ and the Gibbs free energy required in the dissociation reaction of trimeric ion $\left[\mathrm{AB}_{2} \mathrm{Z}_{\mathrm{n}}(\mathrm{II})-\mathrm{H}\right]^{+}$. The relationship was shown in eq 8 as $(-)-\mathrm{O}$ and $(+)-\mathrm{O}$ composing the trimeric cluster ion respectively.

$$
\begin{aligned}
& \Delta G_{[A(-)-B Z n(I I)-H]^{+}}-\Delta G_{\left[A((-)-B)^{2} Z n(I I)-H\right]^{+}} \\
& =R T_{e f f} \ln R_{-}^{\prime \prime} \Delta G_{[A(+)-B Z n(I I)-H]^{+}}-\Delta G_{\left[A((+)-B)_{2} Z n(I I)-H\right]^{+}} \\
& =R T_{e f f} \ln R_{+}^{\prime \prime}
\end{aligned}
$$

Eq 8 would deduce a relationship between $R_{\text {chiral }}^{\prime \prime}$ and Gibbs free energy required in dissociation process of $\left[\mathrm{A}((-)-\mathrm{B})_{2} \mathrm{Z}_{\mathrm{n}}(\mathrm{II})-\mathrm{H}\right]^{+}$and $\left[\mathrm{A}((+)-\mathrm{B})_{2} \mathrm{Z}_{\mathrm{n}}(\mathrm{II})-\mathrm{H}\right]^{+}$respectively.

$$
\begin{aligned}
& \left(\Delta G_{[A(-)-B Z n(I I)-H]^{+}}-\Delta G_{\left[A((-)-B)_{2} Z n(I I)-H\right)^{+}}\right. \\
& \quad-\left(\Delta G_{[A(+)-B Z n(I I)-H]^{+}}-\Delta G_{\left[A((+)-B)_{2} Z n(I I)-B\right]^{+}}\right) \\
& =R T_{\text {eff }}^{-} \ln R_{-}^{\prime \prime}-R T_{e f f}^{+} \ln R_{+}^{\prime \prime}\left(\text { if } T_{e f f}^{-} \text {equal to } T_{\text {eff }}^{+} \text {, then }\right) \\
& \quad=R T_{\text {eff }} \ln \left(R_{-}^{\prime \prime} / R_{+}^{\prime \prime}\right)=R T_{\text {eff }} \ln R_{\text {chiral }}^{\prime \prime}
\end{aligned}
$$

The premise of eq 9 about the identical value of $\mathrm{T}_{\text {eff }}^{-}$and $\mathrm{T}_{\text {eff }}^{+}$is reasonable because $\left[\mathrm{A}((-)-\mathrm{B})_{2} \mathrm{Z}_{\mathrm{n}}(\mathrm{II})-\mathrm{H}\right]^{+}$and $\left[\mathrm{A}((+)-\mathrm{B})_{2} \mathrm{Z}_{\mathrm{n}}(\mathrm{II})-\mathrm{H}\right]^{+}$have the same size and were dissociated in the same experimental condition, especially under the same pressure [58]. Meanwhile, we had more or less concluded that there was no difference of Gibbs free energy between $\left[\mathrm{A}(-)-\mathrm{BZ}_{\mathrm{n}}(\mathrm{II})-\mathrm{H}\right]^{+}$and $\left[\mathrm{A}(+) \mathrm{BZ}_{\mathrm{n}}(\mathrm{II})-\mathrm{H}\right]^{+}$in the range of pressure we applied in the dissociation of trimeric ion $\left[\mathrm{A}_{2} \mathrm{BZ}_{\mathrm{n}}(\mathrm{II})-\mathrm{H}\right]^{+}$. If we introduced this result to the eq 9, a new conclusion would be achieved that the dif- ference of Gibbs free energy between $\left[\mathrm{A}((-)-\mathrm{B})_{2} \mathrm{Z}_{\mathrm{n}}(\mathrm{III})-\mathrm{H}\right]^{+}$and $[\mathrm{A}((+)-$

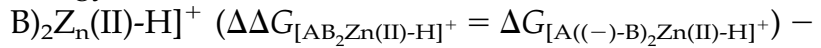
$\Delta G_{\left.\left[\mathrm{A}((+)-\mathrm{B})_{2} \mathrm{Zn}(\mathrm{II})-\mathrm{H}\right]^{+}\right)}$is roughly equal to $-\mathrm{RT}_{\text {eff }} \ln R_{\text {chhiral }}^{\prime \prime}$. This conclusion is useful for us to analyze the intrinsic enantiodiscrimination mechanism of tetrameric cluster ion by the kinetic method, which will be discussed in the following part.

Although we have probed the enantiodiscrimiantion capability of trimeric cluster ion $\left[\mathrm{A}_{2} \mathrm{BZ}_{n}(\mathrm{II})-\mathrm{H}\right]^{+}$by the kinetic method, the difference of Gibbs free energy between $\left[\mathrm{A}_{2}(-)-\mathrm{BZ}_{\mathrm{n}}(\mathrm{II})-\mathrm{H}\right]^{+}$and $\left[\mathrm{A}_{2}(+)-\mathrm{BZ}_{\mathrm{n}}(\mathrm{II})-\mathrm{H}\right]^{+}$ $\left(\Delta \Delta \mathrm{G}_{\left[\mathrm{A}_{2} \mathrm{BZn}(\mathrm{II})-\mathrm{H}\right]^{+}}\right)$could not be directly obtained like the method used in the trimeric ion $\left[\mathrm{AB}_{2} \mathrm{Z}_{\mathrm{n}}(\mathrm{II})-\mathrm{H}\right]^{+}$. The major reasons are that there are two daughter ions in the fragment process of $\left[\mathrm{A}_{2} \mathrm{BZ}_{\mathrm{n}}(\mathrm{II})-\mathrm{H}\right]^{+}$and it is nearly impossible to obtain only one daughter ion like $\left[\mathrm{AB}_{2} \mathrm{Z}_{\mathrm{n}}(\mathrm{II})-\mathrm{H}\right]^{+}$. Even if the dissociation process of only one daughter ion was achieved, too low relative intensity of the ion would result in greater error in evaluating the enantiodiscrimination of the trimeric ion. Thus, the linear relationship between $\Delta \Delta G_{\left[\mathrm{A}_{2} \mathrm{BZn}(\mathrm{II})-\mathrm{H}\right]^{+}}$and relative intensity ratio of the fragment ion $\left[\mathrm{ABZ}_{\mathrm{n}}(\mathrm{II})\right.$ $\mathrm{H}]^{+}$to the parent ion $\left[\mathrm{A}_{2} \mathrm{BZ}_{\mathrm{n}}(\mathrm{II})-\mathrm{H}\right]^{+}$could not be 
obtained based on the experiment data we got in the dissociation process of $\left[\mathrm{A}_{2} \mathrm{BZ}_{n}(\mathrm{II})-\mathrm{H}\right]^{+}$. Fortunately, we could indirectly deduce the value of $\Delta \Delta G_{\left[\mathrm{A}_{2} \mathrm{BZn}(\mathrm{II})-\mathrm{H}\right]^{+}}=$ $\Delta G_{\left[\mathrm{A}_{2}(-)-\mathrm{BZn}(\mathrm{II})-\mathrm{H}\right]^{+}}-\Delta G_{\left[\mathrm{A}_{2}(+)-\mathrm{BZn}(\mathrm{II})-\mathrm{H}\right]^{+}}$based on the eq 5

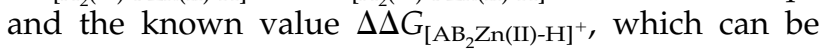
expressed by the following equation (eq 10):

$$
\begin{aligned}
\Delta \Delta G_{\left[A_{2} B Z n(I I)-H\right]^{+}}= & -\left(R T_{\text {eff }} / \ln \left(R_{\text {chiral }}\right)\right. \\
& \left.-\Delta \Delta G_{\left[A B_{2} Z n(I I)-H\right]^{+}}\right) \\
= & -\left(R T_{\text {eff }} \ln \left(R_{\text {chiral }}\right)\right. \\
& \left.+R T_{\text {eff }} \ln \left(R_{\text {chiral }}^{\prime \prime}\right)\right) \\
= & -R T_{\text {eff }} \ln \left(R_{\text {chiral }} \times R_{\text {chiral }}^{\prime \prime}\right)
\end{aligned}
$$

$\Delta \Delta \mathrm{G}_{\left[\mathrm{A}_{2} \mathrm{BZn}(\mathrm{II})-\mathrm{H}\right]^{+}}$should be obtained in the $\mathrm{T}_{\text {eff }}$ of the tetrameric ion as it dissociate two trimeric cluster ion. If we suppose there is a dissociation process of trimeric ion $\left[\mathrm{A}_{2} \mathrm{BZ}_{\mathrm{n}}(\mathrm{II})-\mathrm{H}\right]^{+}$generating only one daughter ion $\left[\mathrm{ABZ}_{\mathrm{n}}(\mathrm{II})-\mathrm{H}\right]^{+}$and define $R_{\text {chiral }}^{\prime \prime}$ as $R_{-}^{\prime \prime} / R_{+}^{\prime \prime}$ in which $R_{-}^{\prime \prime}$ and $R_{+}^{\prime \prime}$ represent the intensity ratio of the fragment ion $\left[\mathrm{ABZ}_{\mathrm{n}}(\mathrm{II})-\mathrm{H}\right]^{+}$to the parent ion $\left[\mathrm{A}_{2} \mathrm{BZ}_{\mathrm{n}}(\mathrm{II})-\mathrm{H}\right]^{+}$with $(-)$-B and (+)-B in it, respectively, $R_{\text {chiral }}^{\prime \prime}(0.51)$ can be obtained by $1 /\left(R_{\text {chiral }} \times R_{\text {chiral }}^{\prime \prime}\right)$, in which $\Delta \Delta G_{[\mathrm{ABZn}(\mathrm{II})-\mathrm{H}]^{+}}$ can also be ignored. Then $R_{\text {chiral }}^{\prime \prime \prime}$ can be applied as an index of evaluating the contribution of $\Delta \Delta G_{[\mathrm{ABZn}(\mathrm{II})-\mathrm{H}]^{+}}$ to the chiral recognition of tetrameric ion by kinetic method. However, the key question is whether the $R_{\text {chiral }}^{\prime \prime}$ achieved from eq 9 can be used in eq 10 because these two reactions are different dissociation processes of different parent ions.

In the study of dissociation of trimeric ion $\left[\mathrm{AB}_{2} \mathrm{Z}_{\mathrm{n}}(\mathrm{II})-\mathrm{H}\right]^{+}$, we have investigated the effect of cell pressure to $R_{\text {chiral }}^{\prime \prime} \cdot R_{-}^{\prime \prime}$ and $R_{+}^{\prime \prime}$ all increase with pressure increasing, which means variations of pressure have to change the $\mathrm{T}_{\text {eff }}$ to the same extent of $R_{-}^{\prime \prime}$ and $R_{+}^{\prime \prime}$ increasing when the Gibbs free energy required in the dissociation process of $\left[\mathrm{AB}_{2} \mathrm{Z}_{\mathrm{n}}(\mathrm{II})-\mathrm{H}\right]^{+}$is invariable. $R_{-}^{\prime \prime}$ and $R_{+}^{\prime \prime}$ both increase in the same trend and extent, which result in stability of $R_{\text {chiral }}^{\prime \prime}$. It is reasonable in that $\left[\mathrm{A}((-)-\mathrm{B})_{2} \mathrm{Z}_{\mathrm{n}}(\mathrm{II})-\mathrm{H}\right]^{+}$and $\left[\mathrm{A}((+)-\mathrm{B})_{2} \mathrm{Z}_{\mathrm{n}}(\mathrm{II})-\mathrm{H}\right]^{+}$have the same size and were dissociated in the same pressure. Thus, we assume, $R_{\text {chiral }}^{\prime \prime}$ in the dissociation process of $\left[\mathrm{AB}_{2} \mathrm{Z}_{\mathrm{n}}(\mathrm{II})-\mathrm{H}\right]^{+}$should be maintained stable in the $\mathrm{T}_{\text {eff }}$ as it is equal to the effective temperature needed in the dissociation reaction of tetrameric ion $\left[\mathrm{A}_{2} \mathrm{~B}_{2} \mathrm{Zn}(\mathrm{II})-\mathrm{H}\right]^{+}$. So, the $R_{\text {chiral }}^{\prime \prime}$ achieved from eq 9 can be used in eq 10 .

Finally, we can use $R_{\text {chiral }}^{\prime \prime}$ and $R_{\text {chiral }}^{\prime \prime \prime}$ as an index to evaluate the Gibbs free energy difference of trimeric cluster ions $\left[\mathrm{A}_{2} \mathrm{BZ}_{\mathrm{n}}(\mathrm{II})-\mathrm{H}\right]^{+}$and $\left[\mathrm{AB}_{2} \mathrm{Z}_{\mathrm{n}}(\mathrm{II})-\mathrm{H}\right]^{+}$, which both contribute to the chiral recognition of tetrameric ion observed in the kinetic method. Obviously, $\left[\mathrm{A}_{2} \mathrm{BZ}_{\mathrm{n}}(\mathrm{II})-\mathrm{H}\right]^{+}\left(R_{\text {chiral }}^{\prime \prime \prime}=0.51\right)$ makes more contribution to chiral recognition of tetrameric ion measured by kinetic method than $\left[\mathrm{AB}_{2} \mathrm{Z}_{\mathrm{n}}(\mathrm{II})-\mathrm{H}\right]^{+}\left(R_{\text {chiral }}^{\prime \prime}=0.81\right)$ does.

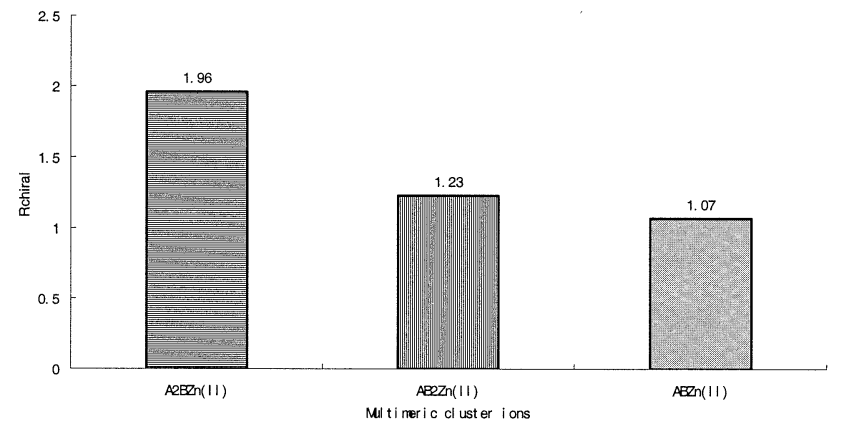

Figure 2. The value $R_{\text {chiral }}$ of different multimeric ions: From left to right are $\left[\mathrm{AB}_{2} \mathrm{Zn}(\mathrm{II})-\mathrm{H}\right]^{+},\left[\mathrm{A}_{2} \mathrm{BZn}(\mathrm{II})-\mathrm{H}\right]^{+}{ }^{\mathrm{a}}$ and $[\mathrm{ABZn}(\mathrm{II})-\mathrm{H}]^{+}$. $R_{\text {chiral }}$ applied for $\left[\mathrm{A}_{2} \mathrm{BZn}(\mathrm{II})-\mathrm{H}\right]^{+}$and $\left[\mathrm{AB}_{2} \mathrm{Zn}(\mathrm{II})-\mathrm{H}\right]^{+}$are calculated by $1 /$ and $1 /$.

\section{Intrinsic Mechanism of Chiral Recognition in the Gas Phase}

As shown in Figure 2, there is a Gibbs free energy difference of the different multimeric cluster ions, i.e., $\left[\mathrm{A}_{2} \mathrm{BZn}(\mathrm{II})-\mathrm{H}\right]^{+},\left[\mathrm{AB}_{2} \mathrm{Zn}(\mathrm{II})-\mathrm{H}\right]^{+}$, and $[\mathrm{ABZn}(\mathrm{II})-\mathrm{H}]^{+}$. In general, the results show that trimeric ion $\left[\mathrm{A}_{2} \mathrm{BZn}(\mathrm{II})\right.$ $\mathrm{H}]^{+}$has the highest degree of chiral resolution of $(+)-B$ and (-)-B among all complex ions because there is a greatest difference of the Gibbs free energy in its diastereomeric ion if $R^{\prime \prime \prime}$ chiral, $R_{\text {chiral, }}^{\prime \prime}$ and $R_{\text {chiral }}^{\prime}$ was applied as an index to evaluate the difference of Gibbs free energy. Chiral discrimination of dimeric cluster ion $[\mathrm{ABZn}(\mathrm{II})-\mathrm{H}]^{+}$are relatively small, probably because it has a much looser structure than trimeric cluster ions, in which the empty orbits of zinc ion are much more occupied by ligands resulting in the greatest interaction between ligands. It has been proposed, in a host-guest systems formed by cyclodextrin and alkyl amino acids, that the enantioselctivity increases rapidly from 1.6 for Ala to 3.6 for Leu, which is explained by the increasing steric repulsion with the alkyl group getting bigger [33]. This explanation has been introduced to describe the nature of enantioselectivity and also has been refined to be called the "three-point interaction" model $[59,60]$. This model easily rationalizes much great chiral recognition capability of trimeric cluster ions. Because both naproxen and Compound A have a relatively big side chain as ligands, there is increased steric repulsion among ligands in the trimeric cluster ion which is forced to adopt a much more specific conformation leading to much higher chiral discrimination. However, another interesting result was also achieved in the comparison of the chiral recogntion capability of trimeric ion between $\left[\mathrm{AB}_{2} \mathrm{Zn}(\mathrm{II})-\mathrm{H}\right]^{+}$and $\left[\mathrm{A}_{2} \mathrm{BZn}(\mathrm{II})-\mathrm{H}\right]^{+}$. Although both of them are formed by the same amount of ligand, they produced a difference between $R_{\text {chiral }}^{\prime \prime}$ and $R_{\text {chiral }}^{\prime \prime \prime}$. The reason, we think, is probably that there are two napthyl group in the trimeric ion $\left[\mathrm{A}_{2} \mathrm{BZn}(\mathrm{II})\right.$ $\mathrm{H}]^{+}$compared with one in $\left[\mathrm{AB}_{2} \mathrm{Zn}(\mathrm{II})-\mathrm{H}\right]^{+}$. It has been proposed that superior chiral recognition is achieved when the reference ligand has an aromatic side chain[38]. Thus, $\left[\mathrm{A}_{2} \mathrm{BZn}(\mathrm{II})-\mathrm{H}\right]^{+}$has a little higher chiral 
recognition capability than $\left[\mathrm{AB}_{2} \mathrm{Zn}(\mathrm{II})-\mathrm{H}\right]^{+}$, which again suggested that the $\pi$ - $\pi$ stacking interactions may play a role in the stereospecificity. These interactions are likely to be between the naphyl ring in one of naproxen and the carboxylate group of the other naproxen.

In summary, we can primarily conclude that steric interactions and of $\pi-\pi$ stacking interactions are the major factors responsible for the observed efficient chiral recognition.

\section{Acknowledgments}

This work was supported by the National Natural Science Foundation of China (no. 20175034), and by the Natural Science Foundation of Shanghai (no. 00ZA14077).

\section{References}

1. von Zelewsky, A. Stereoselective Synthesis of Coordination Compounds. Coord. Chem. Rev. 1999, 190/192, 811-825.

2. Rentsch, K. M. The Importance of Stereoselective Determination of Drugs in the Clinical Laboratory. J. Biochem. Biophys. Methods 2002, 54, 1-9.

3. Devlin, F. J.; Stephens, P. J.; Oesterle, C.; Wiberg, K. B.; Cheeseman, J. R.; Frisch, M. J Configurational and Conformational Analysis of Chiral Molecules Using IR and VCD Spectroscopies: Spiropentylcarboxylic Acid Methyl Ester and Spiropentyl Acetate. J. Org. Chem. 2002, 67, 8090-8096.

4. Schurig, V. Chiral Separations Using Gas Chromatography. Trends Anal. Chem. 2002, 21, 647-661.

5. Tran, C. D.; Kang, J. Chiral Separation of Amino Acids by Capillary Electrophoresis with Octyl-b-Thioglucopyranoside as Chiral Selector. J. Chromatogr. A 2002, 978, 221-230.

6. Malik, S.; Moeller, S.; Duddeck, H.; Choudhary, M. I. Phenylselenenylmenthane Derivatives and Their Enantiomeric Discrimination by $1 \mathrm{H}$ and $13 \mathrm{C}$ NMR Spectroscopy in the Presence of a Chiral Dirhodium Complex. Magnetic Res. Chem. 2002, 40, 659-665.

7. Sawada, M. Chiral Recognition Detected by Fast-Atom-Bombardment Mass-Spectrometry. Mass Spectrom. Rev. 1997, 16, 73-90.

8. Fales, H. M.; Wright, G. J. Detection of Chirality with the Chemical Ionization Mass Spectrometer. "Meso" Ions in the Gas Phase. J. Am. Chem. Soc. 1977, 99, 2339-2340.

9. Shizuma, M.; Adachi, H.; Takai, Y.; Hayashi, M.; Tanaka, J.; Takeda, T.; Sawada, M. Combinatorial Evaluation of the Chiral Discrimination of Permethylated Carbohydrates Using Fast-Atom Bombardment Mass Spectrometry. Carbohydr. Res. 2001, 335, 275-281.

10. Reetz, M. T.; Becher, M. H.; Klein, H-W.; Stöckigt, D. A Method for High-Throughput Screening of Enantioselective Catalysts. Angew. Chem. Int. Ed. 1999, 38(1758), 1761.

11. Garcia, C.; Guyot, J.; Jeminet, G.; Emmanuelle, L. W.; Nierengarten, H.; Dorsselaer, A. V. Chiral Recognition Properties of Spiroacetal Polyethers Using Electrospray Ionization Mass Spectrometry. Tetrahedron Lett. 1999, 40, 4997-5000.

12. Arakawa, R.; Kobayashi, M.; Ama, T. Chiral Recognition in Association Between Antimony Potassium Tartrate and Bis(LAlaninate)Ethylenediamine Cobalt(III) Complexes Using Electrospray Ionization Mass Spectrometry. J. Am. Soc. Mass Spectrom. 2000, 11, 804-808.

13. Krishna, P.; Prabhakar, S.; Manoharan, M.; Jemmis, E. D.; Vairamani, M. Chiral Recognition and the Determination of Optical Purity of Some Amino Acid Ester Salts Using
Monosaccharides as Chiral Selectors Under Liquid Secondary Ion Mass Spectral Conditions. Chem. Commun. 1999, 13, 12151216.

14. Diaz, D. D.; Yao, S.; Finn, M. G. Measurement of Enantiomeric Excess of Amines by Mass Spectrometry Following Kinetic Resolution with Solid-Phase Chiral Acylating Agents. Tetrahedron Lett. 2001, 42, 2617-2619.

15. Guo, J.; Wu, J.; Siuzdak, G.; Finn, M. G. Measurement of Enantiomeric Excess by Kinetic Resolution and Mass Spectrometry. Angew. Chem. Int. Ed. 1998, 38(1755), 1758.

16. Shizuma, M.; Imamura, H.; Takai, Y.; Yamada, H.; Takeda, T.; Takahashi, S.; Sawada, M. A New Reagent to Evaluate Optical Purity of Organic Amines by FAB Mass Spectrometry. Chem. Lett. 2000, 11, 1292-1293.

17. Shizuma, M.; Imamura, H.; Takai, Y.; Yamada, H.; Takeda, T.; Takahashi, S.; Sawada, M. Facile ee-Determination from a Single Measurement by Fast Atom Bombardment Mass Spectrometry: A Double Labeling Method.. Int. J. Mass Spectrom. 2001, 210/211, 585-590.

18. Sawada, M.; Yamaoka, H.; Takai, Y.; Kawai, Y.; Yamada, H.; Azuma, T.; Fujioka, T.; Tanaka, T. Determination of Enantiomeric Excess for Organic Primary Amine Compounds by Chiral Recognition Fast-Atom Bombardment Mass Spectrometry. Int. J. Mass Spectrom. 1999, 193, 123-130.

19. Sawada, M.; Takai, Y.; Yamada, H.; Hirayama, S.; Kaneda, T.; Tanaka, T.; Kamada, K.; Mizooku, T.; Takeuchi, S.; Ueno, K.; Hirose, K.; Tobe, Y.; Naemura, K. Chiral Recognition in Host-Guest Complexation Determined by the EnantiomerLabeled Guest Method Using Fast Atom Bombardment Mass Spectrometry. J. Am. Chem. Soc. 1995, 117, 7726-7736.

20. Sawada, M.; Takai, Y.; Yamada, H.; Nishida, J.; Kaneda, T.; Arakawa, R.; Okamoto, M.; Hirose, K.; Tanaka, T.; Naemura, K. Chiral Amino Acid Recognition Detected by Electrospray Ionization (ESI) and Fast Atom Bombardment (FAB) Mass Spectrometry (MS) Coupled with the Enantiomer-Labeled (EL) Guest Method. J. Chem. Soc. Perkin Trans. 2 1998, 3, 701-710.

21. Sawada, M.; Shizuma, M.; Takai, Y.; Adachi, H.; Takeda, T.; Uchiyama, T. Measurement of Chiral Amino Acid Discrimination by Cyclic Oligosaccharides: A Direct FAB Mass Spectrometric Approach. Chem. Commun. 1998, 14, 1453-1454.

22. Sawada, M.; Takai, Y.; Yamada, H.; Kaneda, T.; Kamada, K.; Mizooku, T.; Hirose, K.; Tobe, Y.; Naemura, K. Chiral Recognition in Molecular Complexation for the Crown Ether-Amino Ester System. A Facile FAB Mass Spectrometric Approach. J. Chem. Soc. Chem. Commun. 1994, 21, 2497-2498.

23. Yao, Z. P.; Wan, T. S. M.; Kwong, K. P.; Che, C. T. Chiral Recognition of Amino Acids by Electrospray Ionization Mass Spectrometry/Mass Spectrometry. Chem. Commun. 1999, 20, 2119-2120.

24. Yao, Z. P.; Wan, T. S. M.; Kwong, K. P.; Che, C. T. Chiral Analysis by Electrospray Ionization Mass Spectrometry/Mass Spectrometry. 1. Chiral Recognition of 19 Common Amino Acids. Anal. Chem. 2000, 72, 5383-5393.

25. Yao, Z. P.; Wan, T. S. M.; Kwong, K. P.; Che, C. T. Chiral Analysis by Electrospray Ionization Mass Spectrometry/Mass Spectrometry. 2. Determination of Enantiomeric Excess of Amino Acids. Anal. Chem. 2000, 72, 5394-5401.

26. Liang, Y.; Bradshaw, J. S.; Dearden, D. V. The Thermodynamic Basis for Enantiodiscrimination: Gas-Phase Measurement of the Enthalpy and Entropy of Chiral Amine Recognition by Dimethyldiketopyridino-18-Crown-6. J. Phys. Chem. A 2002, 106, 9665-9671.

27. Dearden, D. V.; Liang, Y.; Nicoll, J. B.; Kellersberger, K. A. Study of Gas-Phase Molecular Recognition Using Fourier Transform Ion Cyclotron Resonance Mass Spectrometry (FTICR/MS). J. Mass Spectrom. 2001, 36, 989-997. 
28. Liang, Y.; Bradshaw, J. S.; Izatt, R. M.; Pope, R. M.; Dearden, D. V. Analysis of Enantiomeric Excess Using Mass Spectrometry: Fast Atom Bombardment/Sector and Electrospray Ionization/Fourier Transform Mass Spectrometric Approaches. Int. J. Mass Spectrom. 1999, 185/186/187, 977-988.

29. Dearden, D. V.; Dejsupa, C.; Liang, Y.; Bradshaw, J. S.; Izatt, R. M. Intrinsic Contributions to Chiral Recognition: Discrimination Between Enantiomeric Amines by Dimethyldiketopyridino-18-Crown-6 in the Gas Phase. J. Am. Chem. Soc. 1997, 119, 353-359.

30. Chu, I. H.; Dearden, D. V.; Bradshaw, J. S.; Huszthy, P.; Izatt, R. M. Chiral Host-Guest Recognition in an Ion-Molecule Reaction. J. Am. Chem. Soc. 1993, 115, 4318-4320.

31. Grigorean, G.; Ramirez, J.; Ahn, S. H.; Lebrilla, C. B. A Mass Spectrometry Method for the Determination of Enantiomeric Excess in Mixtures of D,L-Amino Acids. Anal. Chem. 2000, 72, $4275-4281$.

32. Grigorean, G.; Lebrilla, C. B. Enantiomeric Analysis of Pharmaceutical Compounds by Ion/Molecule Reactions. Anal. Chem. 2001, 73, 1684-1691.

33. Ahn, S.; Ramires, J.; Grigorean, G.; Lebrilla, C. B. Chiral Recognition in Gas-Phase Cyclodextrin: Amino Acid Complexes-Is the Three Point Interaction Still Valid in the Gas Phase? J. Am. Soc. Mass Spectrom. 2001, 12, 278-287.

34. Grigorean, G.; Gronert, S.; Lebrilla, C. B. Enantioselective Gas-Phase Ion-Molecule Reactions in a Quadrupole Ion Trap. Int. J. Mass Spectrom. 2002, 219, 79-87.

35. Gong, S.; Camara, E; He, F.; Green, M. K.; Lebrilla, C. B. Chiral Recognition and the Deprotonation Reaction of Gas-Phase Cytochrome $c$ Ions. Int. J. Mass Spectrom. 1999, 185/186/187, 401-412.

36. Gal, J. F.; Stone, M.; Lebrilla, C. B. Chiral Recognition of Non-Natural $\alpha$-Amino Acids. Int. J. Mass Spectrom. 2003, 222, 259-267.

37. Tao, W. A.; Zhang, D.; Wang, F.; Thomas, P. D.; Cooks, R. G. Kinetic Resolution of D,L-Amino Acids Based on Gas-Phase Dissociation of Copper(II) Complexes. Anal. Chem. 1999, 71, 4427-4429.

38. Tao, W. A.; Zhang, D.; Nikolaev, E. N.; Cooks, R. G. Copper(II)-Assisted Enantiomeric Analysis of D,L-Amino Acids Using the Kinetic Method: Chiral Recognition and Quantification in the Gas Phase. J. Am. Chem. Soc. 2000, 122, 10598-10609.

39. Tao, W. A.; Gozzo, F. C.; Cooks, R. G. Mass Spectrometric Quantitation of Chiral Drugs by the Kinetic Method. Anal. Chem. 2001, 73, 1692-1698.

40. Tao, W. A.; Wu, L.; Cooks, R. G.; Wang, F.; Begley, J. A.; Lampert, B. Rapid Enantiomeric Quantification of an Antiviral Nucleoside Agent (D,L-FMAU, 2'-Fluoro-5-Methyl- $\beta, D, L-A r-$ abinofuranosyluracil) by Mass Spectrometry. J. Med. Chem. 2001, 44, 3541-3544.

41. Fago, G.; Filippi, A.; Giardini, A.; Laganà, A.; Paladini, A.; Speranza, M. Chiral Recognition of O-Phosphoserine by Mass Spectrometry. Angew. Chem. Int. Ed. 2001, 40(4051), 4054.

42. Vékey, K.; Czira, G. Distinction of Amino Acid Enantiomers Based on the Basicity of Their Dimers. Anal. Chem. 1997, 69, $1700-1705$.

43. Tao, W. A.; Wu, L.; Cooks, R. G. Differentiation and Quantitation of Isomeric Dipeptides by Low-Energy Dissociation of Copper(II)-Bound Complexes. J. Am. Soc. Mass Spectrom. 2001, $12,490-496$.
44. Zhang, D.; Tao, W. A.; Cooks, R. G. Chiral Resolution of Dand L-Amino Aacids by Tandem Mass Spectrometry of Ni(II)Bound Trimeric Complexes. Int. J. Mass Spectrom. 2001, 204, 159-169.

45. Augusti, D. V.; Carazza, F.; Augusti, R.; Tao, W. A.; Cooks, R. G. Quantitative Chiral Analysis of Sugars by Electrospray Ionization Tandem Mass Spectrometry Using Modified Amino Acids as Chiral Reference Compounds. Anal. Chem. 2002, 74, 3458-3462.

46. Tao, W. A.; Cooks, R. G. Chiral Analysis by MS. Anal. Chem. 2003, 75, 25A-31A.

47. Wu, L.; Cooks, R. G. Chiral Analysis Using the Kinetic Method with Optimized Fixed Ligands: Applications to Some Antibiotics. Anal. Chem. 2003, 75, 678-684.

48. Winkler, F. J.; Medina, R.; Winkler, J.; Krause, H. Mass Spectral and Semi-Empirical Studies on Chiral Discimination in Gaseous Aggregation Products of Protonated Didalkyl Tartrates. J. Chromatogr. A 1994, 666, 549-556.

49. Chen, Y.-Z.; Li, H.; Yang, H.-J.; Hua, S.-M.; Li, H.-Q.; Zhao, F.-Z.; Chen, N.-Y. Stereochemical Effects in Mass Spectrometry 7. Determination of Absolute Configuration of Some Organic Molecules by Reaction Mass Spectrometry. Org. Mass Spectrom. 1988, 23, 821-824.

50. Lim, H.-K.; Hsieh, Y. L.; Ganem, B.; Henion, J. Recognition of Cell-Wall Peptide Ligands by Vancomycin Group Antibiotics: Studies Using Ion Spray Mass Spectrometry. J. Mass Spectrom. 1995, 30, 708-714.

51. Deng, H.; Kebarle, P. Bond Energies of Copper Ion-Ligand L Complexes $\mathrm{CuL}_{2}^{+}$Determined in the Gas Phase by Ion-Ligand Exchange Equilibria Measurements. J. Am. Chem. Soc. 1998, 120, 2925-2931.

52. Gatlin, C. L.; Tureček, F.; Vaisar, T. Copper(II) Amino Acid Complexes in the Gas Phase. J. Am. Chem. Soc. 1995, 117, 3637-3638.

53. Gatlin, C. L.; Tureček, F.; Vaisar, T. Gas-Phase Complexes of Amino Acids with $\mathrm{Cu}(\mathrm{II})$ and Diimine Ligands. Part I. Aliphatic and Aromatic Amino Acids. J. Mass Spectrom. 1995, 30, 1605-1616.

54. Gatlin, C. L.; Tureček, F.; Vaisar, T. Gas-Phase Complexes of Amino Acids with $\mathrm{Cu}$ (II) and Diimine Ligands. Part II. Amino Acids with O, N, and S Functional Groups in the Side-Chain. J. Mass Spectrom. 1995, 30, 1617-1627.

55. Cerda, B. A.; Wesdemiotis, C. The Relative Copper(I) Ion Affinities of Amino Acids in the Gas Phase. J. Am. Chem. Soc. 1995, 117, 9734-9739.

56. Lu, H.-J.; Guo, Y.-L. Evaluation of Chiral Recognition Characteristics of Metal and Proton Complexes of Di-o-BenzoylTartaric Acid Dibutyl Ester and L-Tryptophan in the Gas Phase. J. Am. Soc. Mass Spectrom. 2003, 14, 571-580.

57. Zhong, Y.; Lei, X.; Lin, G. Amino Alcohols with the Bicyclo[3.3.0] Octane Scaffold as Ligands for the Catalytic Enantioselective Addition of Dienthylzinc to Aldehydes. Tetrahed. Asymm. 2002, 13, 2251-2255.

58. Laskin, J.; Futrell, J. H. The Theoretical Basis of the Kinetic Method from the Point-of-View of Finite Heat Bath Theory. J. Phys. Chem. A 2000, 104, 8829-8837.

59. Davankov, V. A. The Nature of Chiral Recognition-Is It a 3-Point Interaction? Chirality 1997, 9, 99-102.

60. Booth, T. D.; Wahnon, D.; Wainer, I. W. Is Chiral Recognition a 3-Point Process? Chirality 1997, 9, 96-98. 